\title{
AC 2008-529: QUANTIFYING QUALITY: A MEASUREMENT ATTEMPT FOR RETURN ON INVESTMENT FOR A SMALL ELECTRONICS ENGINEERING TECHNOLOGY PROGRAM
}

Frank Bartonek, Cessna Aircraft Company

Bruce Dallman, Pittsburg State University

James Lookadoo, Pittsburg State University 


\begin{abstract}
This paper offers observations from a faculty student team internship with a NASA Laboratory and an aircraft company in the summer of 2007. Both organizations have alumni employed from the team's home program.

The onsite observations allowed analysis of educational effectiveness for Pittsburg State University's Electronics Engineering Technology (EET) program. Perspectives are included from the company and Pittsburg State's Dean of Technology. Observations concerning program improvements are made for the program's internal consideration. Effectiveness of alumni on the national laboratory's efforts and the bottom line of the company's sales are measured for these external constituents. The overarching goal is to establish some sort of return on investment estimation to the taxpayer constituents of a small engineering technology program. The process described may suggest paths to establishing economic effectiveness metrics for engineering technology programs.
\end{abstract}

The summer of 2007 brought one of the authors an unusual profession development opportunity. This paper presents an overview of events and how circumstance allowed a measure of an academic program's effectiveness. Additional observations representing administrative and corporate viewpoints are given and results are outlined. First, we present some background and an overview of events.

\title{
Background
}

The Electronics Engineering Technology program at Pittsburg State University offers a four year degree in basic electronics. The program's institution has approximately 7,000 enrolled and is located in a rural part of the state of Kansas. Overall, the institution has seen a steady slow growth. Current program enrollment is slightly above sixty people and trends have been slowly downward for the last two decades. There are 3.5 FTE faculty members for the program. Demand for program graduates has exceeded supply for most of the past decade.

One of the challenges teaching Electronics Engineering Technology in a relatively isolated area is professional development. The rural setting has advantages for life style but presents a challenge for maintaining technical currency. Meeting this challenge coupled with a fascination with aerospace has led one of the authors to participate in a series of summer faculty experiences with the space agency. Several of these opportunities were with programs coordinated through ASEE and have been vitally important in development and also offering opportunity for students. The latest opportunity involved a year and a half experimental program at NASA Goddard Space Flight Center in Greenbelt, MD. Eight teams comprised of a faculty member and one or 
more students were invited to tackle problems for ten weeks in the summer of 2006 and for five weeks in the summer of 2007.

Being in temporary residence with a group focused upon innovations in satellite communications allowed the student/faculty team a chance to see first hand the effect two former students in the program were having on the NASA lab host group, the Communications, Standards, and Technology Laboratory (CSTL). CSTL is evolving from a focus on innovations with the Tracking and Data Relay Satellite System (TDRSS) to innovative communications solutions for the return to the moon effort and other missions. Two Pittsburg State EET alumni started their careers with the space agency in this laboratory group. From an inside perspective, it was easy to track their past footprints on the group's communications effort. One of the alumni has completed a doctorate in electrical engineering and an MBA degree. He was serving as a communications theoretical consultant for the group. The second alumnus is in process of finishing an MSEE degree while he was leading the advanced Field Programmable Logic Array programming. Both had key roles and together represented about ten percent of the human capital in the CSTL enterprise. Putting a dollar amount on the total alumni impact is somewhat imprecise. TDRSS is approximately a two billion dollar investment. The bulk of that is contracted with aerospace industries and must be prorated over the entire satellite system's lifespan. Using conservative figures, an annual estimate of about $\$ 5$ million of linked economic activity per alumni is supportable.

It was obvious from on site observation that our alumni effort contribution exceeded ten percent of the total effort. There are significant parts of the TDRSS system support that are derived from our program's alumni efforts. This was a remarkable observation of alumni effectiveness. The NASA opportunity concluded late in June and the team's focus switched closer to home with a move to Wichita, Kansas.

As preparations were underway to tackle the NASA program, the dean of the College of Technology at Pittsburg State inquired if there might be a willingness to tackle a novel type of faculty internship with a Wichita, KS aircraft company. The company, Cessna Aircraft, has been the employer of the largest percentage of EET graduates over the last decade.

While the intention had been for a full summer's experience with Cessna, the company was willing to consider a reduced six week posting. Furthermore, they were willing to accept the faculty and student team. We had the challenge of changing location, changing jobs, changing technical focus for a third time within a two month period.

Cessna Aircraft Company is headquartered in Wichita, KS. The company manufactures a range of products from single engine sport aircraft to medium scale business jets. With the exception of the latest composite sport utility aircraft, the Skycatcher, production is Kansas based. In 2006, Cessna Aircraft had $\$ 4.2$ billion in sales. In that same year, the Gross State Product for Kansas was given as $\$ 94.6$ billion. Cessna sales represent $4.4 \%$ of that total amount. The fiscal impact is also growing. While on site last 
summer, the company announced they had surpassed $\$ 10$ billion in orders for new aircraft. Six months later, that figure has grown to approximately $\$ 12$ billion.

Designing \& building aircraft is a sizeable undertaking involving large numbers of people. One of the Cessna departments providing engineering support is Avionics and Electrical Systems (AES) which was comprised of 212 people as of August 2007. These people represent the company's resource to sustain existing aircraft, design new systems for existing and new aircraft models, and resolve field service problems. The electrical and avionics systems under control of the AES department conservatively represent a quarter of the value of the aircraft. At least a billion dollars of annual sales is attributed to the work of AES. A check of the AES roster determined that $10.5 \%$ of the department personnel were alumni of the EET program at Pittsburg State. Prorated equally, the figures indicate that our 22 alumni were linked to over a \$100 million amount of the annual business. It was a very noteworthy finding. Even erring on the conservative side, one could argue over a million dollar economic impact per employee.

\section{Accreditation Impacts}

The EET program was facing a TAC of ABET program review in the fall of 2007. That prospect allowed a heightened focus on several key accreditation factors. Specifically, the faculty member of the team recognized an opportunity to note specifics on how EET alumni were utilizing the required attribute components of program objectives (the "a-k" list) on the job. Additionally, job responsibilities for alumni make strong arguments that the program's longer term educational objectives are being met. Finally, the encounters with alumni offered a way to assess how the professional society mandated outcomes (in our case, the IEEE's outcomes for Electrical/Electronic(s) Engineering Technology) were needed in the job settings.

To capture these items, the faculty/student team kept a summary log of examples of "a-k" attributes observed with the alumni as well as examples of the five program specific outcomes. These were then detailed in the documents used to report summer activity reports to the two organizations. The report to Cessna also contained a section that expanded the attributes to include tie-ins to an international concordance of accrediting societies addressing engineering technology, the Sydney Accord. This was provided to the company as an aid to evaluating international credentials in potential employees from around the globe.

Copies of the reports were included as exhibit materials for the visiting team and were helpful in making the case that the EET program was meeting its educational objectives. Moreover, the data gathered suggests a modification of the existing curriculum to increase the value of future graduates. The numbers justify the addition of an aerospace electronics emphasis area tuned to corporate needs as a new element of the EET program. 


\section{A Company Perspective}

Product Engineering is the engine which drives new aircraft model development and in turn sustained growth at Cessna Aircraft. Designing aircraft systems is a demanding profession. At Cessna, we constantly strive to design safe, reliable and cost effective aircraft systems for our customers. We have to get our designs right before proceeding to production. Our customers literally trust their lives to our designs. Our customers demonstrate their trust each time they operate their aircraft. Integrity, exceeding customer expectations, meeting schedule commitments and teamwork are all part of the engineering culture here at Cessna. One might believe our high customer and internal expectations would promote a high stress work environment. Yet, we have a very desirable working condition. These things do not appear compatible at first blush. What makes this possible?

I have enjoyed working in the Avionics \& Electrical Systems Department of Cessna Product Engineering for over twenty-nine years. During the past decade, one of my ongoing assignments has been the recruitment of engineering talent for my department. While the AES department is a relatively small part of the company, our designs contribute significantly to overall customer satisfaction, safety and value of the aircraft we produce. Success requires a focus on practical engineering skills, dedication, knowledge of a multitude of standards issues, creativity tempered with defined company practices, and sound engineering judgment. Where do you find people with such traits willing to live in the central plains of the United States? If you do find sources, how do you maintain and nurture those sources to meet a growing demand for good engineering talent? These questions are ones upon which I and Cessna maintain focus. Good answers to these questions help insure the continued success of our multibillion dollar company.

Cessna Aircraft has a global customer base and a global reach. However, we have experienced difficulties with both recruitment and retention of engineering talent from areas beyond the Midwest. We have found it very beneficial to partner with engineering programs in our state and surrounding states. Pittsburg State's Electronics program is one of those programs. Their graduates have proven consistently to be a good match with our needs. Perhaps even more important than the match is long term loyalty. Our Pittsburg State employees rarely leave our organization and this is an increasingly rare characteristic.

The slowly declining enrollment numbers in Pittsburg State's EET program (and in other programs) is a concern and certainly has a potential threat for us. I annually track these numbers and always attend recruiting fairs and other opportunities to keep our company in the minds of Pittsburg State engineering students. I also serve on the Pittsburg State University College of Technology advisory committee. The college had a new dean and he had approached me about possibly working to get his faculty into Cessna and Cessna engineers into PSU classrooms. This immediately seemed a useful way to strengthen ties and increase opportunities for better visibility and better understanding of the recruiting problems. We would be open to this possibility and I pushed to get this approved through our company hierarchy. 


\section{A Dean's Perspective}

Pittsburg State University is an organized campus, with the faculty represented by the Kansas National Education Association. The organization of the faculty took place over three decades ago and at the time; there were some very contentious issues that probably in themselves helped the organization effort. But as many of you know, there are good things that come out of an organized faculty, and that is very well described expectations of all that are associated with the institution. Also, an organized campus has a tendency to be much more deliberate in issues of strategic mission and goals for the institution. Why are these issues important? I believe this is important in that PSU has not forgotten or been dissuaded from what it has held so important for its history. Simply stated, quality teaching and real concern for the futures of its graduates.

While I have been at PSU a relatively short 18 months, it was very clear to me early on that teaching and service to students is by far the highest priority of activities for faculty, staff and administrators. Faculty, staff, administrators, and especially students are extremely loyal to the institution - and with that, we are lucky to have relatively low turnover of faculty, staff, and very good retention rates.

In my humble opinion, the strength of programs, the quality of programs is a combination of several factors. Those include administrative support (generally centered around appropriate funding - but there are other areas as well), quality of instructional facilities (to include equipment in teaching laboratories), level of support services (computing, financial aid offices, registrar, etc.), a strong supply of capable students, and lastly the key component - the quality of faculty. The activities described above are all about maintaining and enhancing the quality of faculty.

When faculty are hired within PSU's College of Technology, appropriate academic credentials as well as industrial experience are expected. Generally speaking, the minimum level of responsible industrial experience is three years. A large percentage of our faculty have significantly more industrial experience than our expected minimum, however even with that, when you consider the low turnover rate of faculty, the time since a faculty's last significant industrial (in plant or facility) experience may actually be quite long. If you factor that with the strongly held philosophy of quality teaching and up to date experiences for students, it seems that in the realm of faculty development for those in very technical fields, that current experiences in the industries that we profess would be an appropriate goal. This is obvious; however there are additional benefits from a program that gets faculty back out into industry to "refresh" their experiences.

Those may include:

- When faculty get the opportunity to spend time in an industrial setting, if appropriate consider taking a student or two with you to share the experience. Some care must be taken to get the right student(s) to come along, but an upper classperson seems to be appropriate for the experiences. This is not to replace a 
formalized internship for the student (many of our programs if not require internships, at least strongly encourage them)

- As any accredited programs know, assessment is a critical part of the continuous improvement expected by our accreditation agency. That assessment can be, and should be, made up of varying criteria measured both during the educational experience of the student as well as after graduation. The experiences explained above gave the EET program vital information which helped build appropriate documentation for Criterion 3 - Assessment and Evaluation.

- Another area concerning accreditation centers on Criterion 5 - Faculty (in the case of TAC-ABET requirements or sections 6.5.1 (b \& c) (in the case of NAIT requirements). Overall competence of the faculty is covered within this criterion and standards, and certainly the activities of faculty completing an internship in industry would be looked favorably upon by a visiting program evaluator. Activities such as what has been described are very much centered around "industrial professional experience" or "applied industrial experience".

- When spending time back in industry, faculty may see firsthand opportunities for either modification of their existing academic program, or may see the need for the development of new concentrations to be offered within the existing major. If it does seem like the opportunity does indeed exist for new curricular development, the advantage that the faculty has which has just returned from a internship is that they have been able to build new, renew, or strengthen existing relationships with the industry - which in turn may lead to increased program support, both financial for new equipment needs - as well as a stronger tie for future graduates for potential placement within the industry.

- Another possible benefit may be to (as in the case just mentioned) have the opportunity to develop data which helps defend attacks against programs that at times are construed as too expensive for universities to maintain. Having data which indicates the strong economic impact of graduates of your program can provide a very strong shield against those "credit hour bean-counters" which have little desire to understand the need for your program.

With the abovementioned benefits you all are now believers of industrial internships ... right? Well, we are certainly not the first to try to develop internships, and as one reviewsthe literature about the concept, those that have attempted this and have written about their experiences mirrored the many benefits of the practice. Many authors however stated that industrial internships were difficult to develop (ties to the industries were hard to establish), very hard to match up to faculty schedules, and did not match up well with expectations for promotion and tenure - especially at research intensive universities. I do not question their writings or experiences. They all provided valid points. What our experiences suggest however is that even with all of the potential difficulties, the results are very much worth the effort. Give it a try - I think if you are successful, you will be very pleased with the results. 


\section{A Few Final Notes}

After summarizing the experiences and considering the perspectives of two of the major constituents in last summer's activities, there are a few final notes that are worthy of attention.

While the interactions of the student and the faculty with the organizations were not detailed in this paper, the team aspect was highly effective for both the student and the faculty team members. This effectiveness, as is usually the case for successful teams, allowed more than a doubling of effect. A Student/Faculty team in internship situations has much to offer and was a positive factor in the enterprise.

Several program specific TAC/ABET criteria have proposals to mandate the use of standards as part of the education. "Electrical/Electronics" is one such program. If this is finally adopted, experiences such as this last summer become even more valuable for incorporating standards examples useful to large constituent industries.

The aircraft industry hosting our team has the distinction of employing the largest percentage of our alumni graduated in the past twelve years. Fifteen percent of our graduates are employed at Cessna. There are other graduates in aviation companies boosting our overall percentage to approximately twenty percent. Considering this, establishing an avionics emphasis area for our program seems to make a possible growth strategy. This is being examined at the current time.

The last, and most salient, note ties to economic impact. The faculty author has been contemplating a means to measure economic impact of the EET program as a possible defense against credit hour counters who will undoubtedly begin to question the viability of a program with declining numbers. While such an argument would be inappropriate for programs such as liberal arts, a professional program that can document its return on investment to the taxpaying stakeholder has a better position to withstand potential criticism linked to declining numbers in enrollment. The experience this summer has spawned a plan to more completely measure the EET program's impact on the state's business and its leverage on tax support received.

\section{References}

1. 2007-2008 Criteria for Accrediting Engineering Technology Programs, Technology Accrediting Commission of ABET, March 18, 2007.

2. CESSNA Press Release RE: Aviation Consumer, August 6, 2007.

3. http://eric.textron.com/, CESSNA Web Site.

4. Avionics and Electrical Systems (AES) Dept 371/372 Organization Chart, per WWWWW. 
5. http://www.bea.gov/newsreleases/regional/gdp_state/gsp_newsrelease.htm, Web site for US Department of Commerce Bureau of Economic Analysis, News release, June 2007.

6. Lookadoo, J. and A. Wolfe, "A Case Study - Summary Report to Cessna," September 2007.

7. Lookadoo, J. and A. Wolfe, "Lunar Surface Communications in a Network EnvironmentSummary of Development plans Supporting Lunar Exploration Communications Test Bed for GSFC Code 567," June 2007.

8. Graduate Competencies and Professional Competencies, Engineering Technologists Mobility Forum, Version 1.1, June 13, 2005. 